\title{
Thermotropic mesomorphism in catanionic surfactants synthesized from quaternary ammonium surfactants and sodium dodecylbenzenesulfonate: Effect of chain length and symmetry
}

Robin Jose, ${ }^{{ }^{*}}$ Tilesh Jayantilal Patel, ${ }^{a 1}$ Troy Allen Cather, ${ }^{a 2}$ Daniel Joseph Willhelm, ${ }^{a}$ Janusz Grebowicz, ${ }^{a}$ Haesook Han, ${ }^{b}$ Pradip Kumar Bhowmik, ${ }^{b}$ Lewis Sharpnack, ${ }^{c}$ Dena Mae AgraKooijman, ${ }^{c}$ and Satyendra Kumar ${ }^{c}$

${ }^{a}$ Department of Natural Sciences, University of Houston-Downtown, One Main Street, Houston, TX 77002-1001, USA., ${ }^{\mathrm{b}}$ Department of Chemistry and Biochemistry, University of Nevada at Las Vegas, 4505 Maryland Parkway, Box 454003, Las Vegas, NV 89154-4003, USA., and ${ }^{\text {c }}$ Department of Physics, Kent State University, Kent, OH 44242, USA

*Corresponding Author: Robin Jose. E-mail: Joser@uhd.edu; Tel.: +1 713221 8115; Fax: +1 7132237476

Tilesh Jayantilal Patel (E-mail: tpatel5801@gmail.com), Troy Allen Cather (E-mail: troyallencather@yahoo.com,Daniel Joseph Willhelm (E-mail:dwillhelm06@gmail.com ), JanuszGrebowicz (E-mail: grebowiczj@uhd.edu), HaesookHan (hanh3@unlv.nevada.edu), Pradip Kumar Bhowmik (E-mail: pradip.bhowmik@unlv.edu), Lewis Sharpnack (E-mail: lsharpna@kent.edu),Dena Mae Agra-Kooijman (E-mail: dagrako@kent.edu), and Satyendra Kumar(E-mail: skumar@kent.edu)

\footnotetext{
${ }^{1}$ Present address: C.T. Bauer College of Business, University of Houston, 4800 Calhoun Rd, Houston, TX 77004, USA.

${ }^{2}$ Present address: 324 Pine Hollow Rd, Liberty, TX 77575, USA.
} 


\section{ABSTRACT:}

Thermotropic properties of catanionic surfactants are influenced by the headgroups as well as hydrocarbon chains. A series of eight catanionic surfactants were synthesized from quaternary ammonium surfactants as the cationic counterpart and dodecylbenzenesulfonate (DBS) as the anionic counterpart and their structures and purities established. Thermal Gravimetric Analysis (TGA), Differential Scanning Calorimetry (DSC), Hot-Stage Polarized Light Microscopy (HSPLM), and X-ray Diffraction (XRD) were used to characterize the thermal and liquid crystalline properties of the derived catanionic surfactants. These surfactants form hexagonal columnar $\left(\mathrm{Col}_{\mathrm{h}}\right)$ phase before isotropization. Their phase behavior is rather complex depending on the chain length, symmetry, and number of chains. In all these surfactants, the thermal stability is influenced by the nature of the headgroup. Mesomorphism on the other hand is a result of the interplay between headgroup interactions and chain interactions. In general, formation of mesophases at lower temperature is favored as the number of $\mathrm{CH}_{2}$ groups per molecule is increased.

KEYWORDS: Catanionic surfactant; Mesophase structure; Hexagonal columnar phase; Room temperature liquid crystal; Amphiphilic liquid crystal

\section{ABBREVIATIONS ${ }^{3}$}

3 Dodecylbenzenesulfonate (DBS); Sodium dodecylbenzenesulfonate (SDBS); Thermal Gravimetric Analysis (TGA); Differential Scanning Calorimetry (DSC); Hot-Stage Polarized Light Microscopy (HSPLM); X-ray Diffraction (XRD); bis(2-ethylhexyl)sulfosuccinate (AOT); didodecyldimethylammonium bromide (DDAB); Liquid Crystalline (LC); Enthalpy of isotropization $\left(\Delta \mathrm{H}_{\mathrm{i}}\right)$; Total enthalpy in the observed temperature range $\left(\Delta \mathrm{H}_{\mathrm{ovr}}\right)$; Entropy of isotropization $\left(\Delta \mathrm{S}_{\mathrm{i}}\right)$; Total entropy in the observed temperature range $\left(\Delta \mathrm{S}_{\text {ovr }}\right)$; Temperature of isotropization $\left(\mathrm{T}_{\mathrm{i}}\right)$; Room temperature (RT); Hexagonal columnar $\left(\mathrm{Col}_{\mathrm{h}}\right)$; Full-width-halfmaximum (FWHM). 


\section{INTRODUCTION}

Surfactants with oppositely charged headgroups are paired to make catanionic surfactants [1]. These surfactants are different from an equimolar mixture of cationic and anionic surfactants, here in called catanionic mixture, in which the associated inorganic counterions are not removed [2]. Catanionic surfactants show properties that are different from their constituents [3]. During catanionic surfactant formation from their constituent surfactants, strong headgroup interaction lowers the enthalpy and the release of the associated counterions to the bulk solution increases the entropy and favor its formation [2,3]. The release of counterions also increases the Debye screening length and makes the electrostatic interactions between the headgroups stronger. In aqueous solutions of these surfactants, micelles and vesicles are found to co-exist and their formation is governed by the critical packing parameter equation [4]. Thus, a catanionic surfactant resulting from two surfactants of different chain length may have favorable curvature required for the vesicle formation. In aqueous catanionic mixtures when the mixing ratios of the two constituent surfactants are different from equimolarity, they form thermodynamically stable vesicles at low surfactant concentration $[5,6]$.

Generally, in aqueous systems, catanionic surfactants separate into a dilute solution and a solid precipitate [7]. Catanionic surfactant derived from equimolar Sodium bis(2ethylhexyl)sulfosuccinate (AOT) and didodecyldimethylammonium bromide (DDAB) is reported to form a reverse hexagonal LC phase in water in high concentration regions of the phase diagram [8]. A similar hexagonal LC phase was observed in the didodecyldimethylammonium AOT catanionic surfactants in solid state without the presence of water [9]. 
In solid state, amphiphilic molecules exhibit various phase transitions upon heating due to the conformational disordering of the alkyl chain and bidimensional disordering of the ionic layer. Catanionic surfactants derived from single-chain quaternary ammonium and single-chain alkylsulfate show increase in phase transition temperature with respect to increase in chain length [10]. Factors such as asymmetry in the hydrocarbon chain length, the nature of the headgroup including the charge density, and the packing effect of the hydrocarbon chain are found to influence solid state thermal transitions in these compounds [9,11-13]. The appearance of the liquid crystalline (LC) phase in non-anisometric and non-amphiphilic molecules has also been reported to be dependent on the number of chains and their length [14-16].

Smectic LC phases have been observed in solid state phase transitions in catanionic surfactants containing alkyl trimethylammonium or pyridinium catanionic counterparts with alkylsulfonate, alkylbenzenesulfonate, and alkanoate [12]. Despite the interesting phase behavior, studies of their thermotropic properties are rare. In a previous study done in our group, it was observed that varying the chain length and number of chains on the quaternary ammonium group affected the mesophase structures and phase transition temperatures in these surfactants [9]. The use of the bulky anion AOT in the above study decreased the phase transition temperatures and some of the reported surfactants had honey-like consistency at room temperature. Interestingly, all the reported surfactants in the above study exist as room temperature liquid crystals. Previous studies on catanionic surfactants derived from linear surfactant counterparts showed that the structure of the alkyl chain of the anionic counterpart can influence the transition temperatures as well as mesophase textures. However, more studies are needed to fully understand the structure-property relationship in these materials. These are interesting materials for theoretical and practical applications [17-21]. 
Herein we report the effect of varying the chain length and number of alkyl chains on the quaternary ammonium counterpart on the thermotropic properties of pseudo double-chain and pseudo triple-chain catanionic surfactants. These surfactants are derived from alkyltrimethylammonium bromide, $\left(\mathrm{CH}_{3}\right)_{3} \mathrm{NRBr}$, and dialkyldimethylammonium bromide, $\left(\mathrm{CH}_{3}\right)_{2} \mathrm{NR}_{2} \mathrm{Br}$, respectively, with sodium dodecylbenzenesulfonate (SDBS).

\section{MATERIALS AND METHODS}

\subsection{Chemicals}

Dodecyltrimethylammonium bromide, trimethylteradecylammonium bromide, hexadecyltrimethylammonium bromide, trimethyloctadecylammonium bromide, didodecyldimethylammonium bromide, dimethylditetradecylammonium bromide, dihexadecyldimethylammonium bromide, and dimethyldioctadecylammonium bromide were purchased from TCI America. SDBS was obtained from TCI America and was purified according to the method reported by Somasundaran et al. [22]. Methylene chloride was obtained from Fisher Scientific Company. The structures of the synthesized compounds are represented in Fig. 1. 


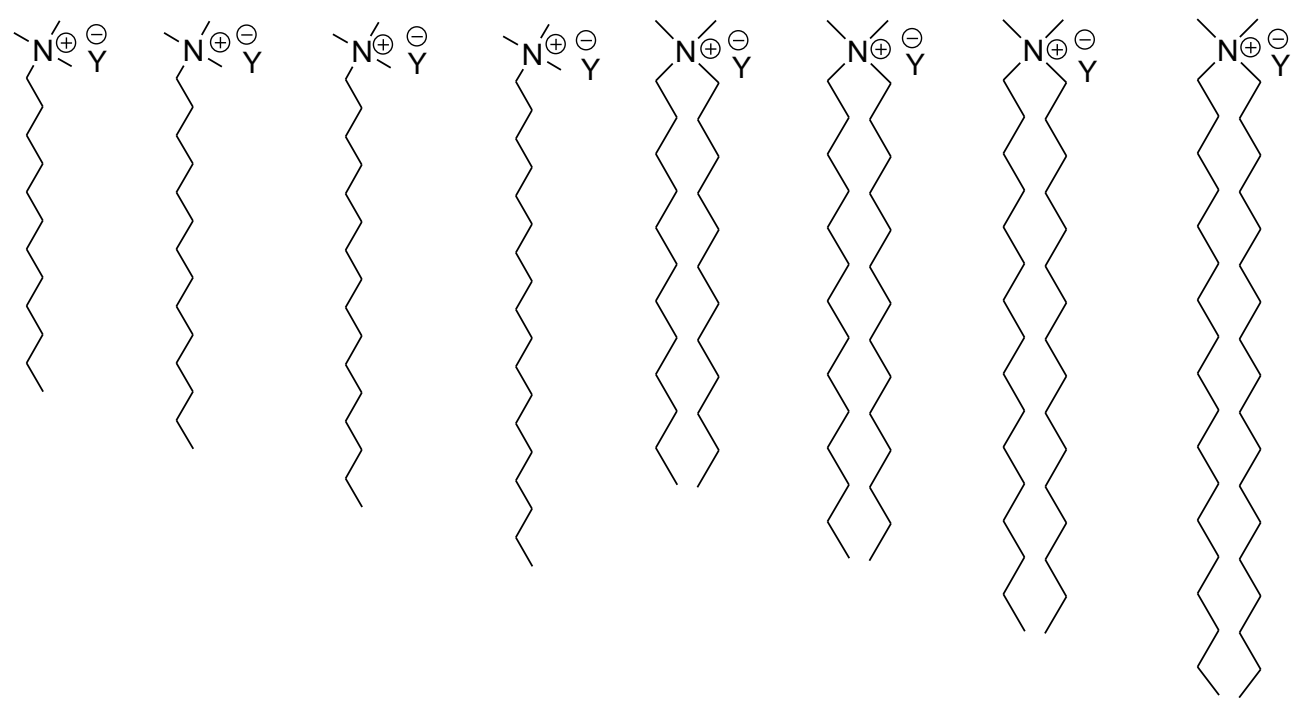

$\mathrm{N}\left(\mathrm{C}_{12}\right)$ DBS N($\left(\mathrm{C}_{14}\right)$ DBS N($\left(\mathrm{C}_{16}\right)$ DBS N $\left(\mathrm{C}_{18}\right)$ DBS N $\left(\mathrm{C}_{12}\right)_{2}$ DBS N $\left(\mathrm{C}_{14}\right)_{2}$ DBS N $\left(\mathrm{C}_{16}\right)_{2}$ DBS N $\left(\mathrm{C}_{18}\right)_{2}$ DBS

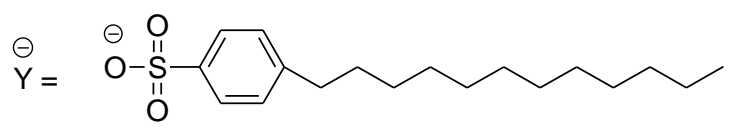

Fig. 1. The molecular structures of the catanionic surfactants dodecyltrimethylammonium DBS; $\mathrm{N}\left(\mathrm{C}_{12}\right) \mathrm{DBS}$, trimethyltetradecylammonium DBS; $\mathrm{N}\left(\mathrm{C}_{14}\right) \mathrm{DBS}$, hexadecyltrimethylammonium DBS; $\quad \mathrm{N}\left(\mathrm{C}_{16}\right)$ DBS, $\quad$ trimethyloctadecylammonium $\quad$ DBS; $\quad \mathrm{N}\left(\mathrm{C}_{18}\right)$ DBS, didodecyldimethylammonium DBS; $\quad \mathrm{N}\left(\mathrm{C}_{12}\right)_{2} \mathrm{DBS}$, dimethylditetradecylammonium DBS; $\mathrm{N}\left(\mathrm{C}_{14}\right)_{2} \mathrm{DBS}, \quad$ dihexadecyldimethylammonium $\quad \mathrm{DBS} ; \quad \mathrm{N}\left(\mathrm{C}_{16}\right)_{2} \mathrm{DBS}$, dimethyldioctadecylammonium DBS; $\mathrm{N}\left(\mathrm{C}_{18}\right)_{2} \mathrm{DBS}$.

\subsection{Syntheses}

In a typical procedure, equimolar solutions of the corresponding quaternary ammonium compound and SDBS in dichloromethane were mixed in an Erlenmeyer flask while being stirred. The resulting hazy solutions were then transferred into a separatory funnel and washed several times with deionized water until the washings were free of bromide ions. This was tested by aqueous $\mathrm{AgNO}_{3}$ solution. The organic phase was then separated, dried using anhydrous sodium 
sulfate, filtered, and evaporated to get a waxy residue, which was then dried under vacuum at elevated temperatures. Analytical purities of these samples were established by elemental analyses performed by Atlantic Microlab, Norcross, GA. Elemental analyses results are shown in Table S1 in the Supplementary Materials.

\subsection{Characterization}

\subsubsection{Thermal Analysis}

Thermal Gravimetric Analysis (TGA) was performed with a Netzsch STA 409 CD using 5-10 mg sample at a heating rate of $10{ }^{\circ} \mathrm{C} / \mathrm{min}$ under $\mathrm{N}_{2}$ atmosphere. Differential Scanning Calorimetry (DSC) was carried out using a Netzsch DSC 200 F3. The samples were placed in an aluminum capsule and were heated and cooled at the rate of $10^{\circ} \mathrm{C} / \mathrm{min}$ under $\mathrm{N}_{2}$ atmosphere. Measurements were made in the temperature range of $\quad-30{ }^{\circ} \mathrm{C}$ to $200{ }^{\circ} \mathrm{C}$. The resulting thermograms were analyzed above $25^{\circ} \mathrm{C}$ using Proteus software.

\subsubsection{Polarized Light Microscopy}

LC textures using Hot-Stage Polarized Light Microscopy (HSPLM) were observed with a Laborlux 12 POL S polarizing light microscope equipped with a Mettler FP52 hot stage controlled by a Mettler FP5 temperature controller. The pictures were obtained using a Leica DFC425 C camera. The obtained photomicrographs were analyzed using Leica Application Suite v.4.1 software.

\subsubsection{X-Ray Diffraction}

LC phase structure identifications using X-Ray Diffraction (XRD) was performed at Kent State University and at the National Synchrotron Light Source, Brookhaven National Laboratory. X-ray diffraction (XRD) measurements were made on double-chain, $\mathrm{N}\left(\mathrm{C}_{\mathrm{n}}\right) \mathrm{DBS}$, and triplechain, $\mathrm{N}\left(\mathrm{C}_{\mathrm{n}}\right)_{2} \mathrm{DBS}$, for $\mathrm{n}=12-18$ (even) contained in flame sealed quartz capillary $(1 \mathrm{~mm})$. 
Initial X-ray scattering measurements were performed using the Rigaku Screen Machine with microfocus sealed X-ray tube with copper anode $(\lambda=1.542 \AA)$ and a Mercury 3 CCD detector with resolution $1024 \times 1024$ pixels (size: $73.2 \times 73.2 \mu \mathrm{m}^{2}$ ). The sample was placed at $63.3 \mathrm{~mm}$ from the detector. Bending magnet $9.05 \mathrm{KeV} \mathrm{X-ray}(\lambda=1.371 \AA)$ beam was used at the NSLS (beamline $\mathrm{X} 27 \mathrm{C}$ ) to improve signal to noise ratio of the weak scattering peaks. The $2 \mathrm{D}$ diffraction patterns were taken using high resolution MARCCD 2D detector with a resolution of $2048 \times 2048$ and pixel size of $79 \times 79 \mu \mathrm{m}^{2}$, positioned approximately $177.3 \mathrm{~mm}$ away from the sample.

The capillary containing the compound was placed between a pair of permanent rare earth magnets inside the hot stage (INSTEC model HS402) and sample temperature controlled with a precision of $\pm 0.1{ }^{\circ} \mathrm{C}$. The samples were exposed 20 seconds for each measurement. The $2 \mathrm{D} \mathrm{X}$ ray patterns were analyzed using the software FIT2D [23] after subtracting the background measured with an empty capillary in the sample position. The data was calibrated against a silver behenate standard traceable to the National Institute of Standards and Technology.

\section{RESULTS AND DISCUSSION}

\subsection{TGA.}

Thermal stabilities of the derived surfactants were studied by TGA, which measures the mass loss upon heating. As represented in Figs. S1 and S2 in the Supplementary Materials, the TGA results show similar decomposition pattern and thermal stability for both the double- and triplechain surfactants. The triple-chain surfactants exhibited faster decomposition at 5\% mass loss compared to the double-chain surfactants as seen in Figures S1 and S2. All the double-chain surfactants showed high thermal stability until approximately $280^{\circ} \mathrm{C}$. After that the samples began to undergo pyrolysis beginning with $\mathrm{N}\left(\mathrm{C}_{14}\right)$ DBS. The $5 \%$ mass loss for $\mathrm{N}\left(\mathrm{C}_{12}\right)$ DBS was at 
$299{ }^{\circ} \mathrm{C}, \mathrm{N}\left(\mathrm{C}_{14}\right)$ DBS at $282{ }^{\circ} \mathrm{C}, \mathrm{N}\left(\mathrm{C}_{16}\right)$ DBS at $291{ }^{\circ} \mathrm{C}$, and $\mathrm{N}\left(\mathrm{C}_{18}\right)$ DBS at $293{ }^{\circ} \mathrm{C}$. The highest thermal stability was observed for $\mathrm{N}\left(\mathrm{C}_{12}\right) \mathrm{DBS}$, while the lowest thermal stability was observed for $\mathrm{N}\left(\mathrm{C}_{14}\right) \mathrm{DBS}$ in this series. All the double-chain surfactants exhibit similar rates of decomposition within the series. This same trend is observed for the triple-chain surfactants as well. The $5 \%$ weight loss for $\mathrm{N}\left(\mathrm{C}_{12}\right)_{2} \mathrm{DBS}$ was at $277^{\circ} \mathrm{C}, \mathrm{N}\left(\mathrm{C}_{14}\right)_{2} \mathrm{DBS}$ at $248^{\circ} \mathrm{C}, \mathrm{N}\left(\mathrm{C}_{16}\right)_{2} \mathrm{DBS}$ at $276{ }^{\circ} \mathrm{C}$, and $\mathrm{N}\left(\mathrm{C}_{18}\right)_{2} \mathrm{DBS}$ at $279{ }^{\circ} \mathrm{C}$. A comparison at $5 \%$ mass loss shows that the double-chain series is more thermally stable than the triple-chain series. In both series, $\mathrm{C}_{14}$ had the lowest thermal stability. It is noteworthy that in a previous study reported from our lab, the $\mathrm{N}\left(\mathrm{C}_{14}\right) \mathrm{AOT}$ had the lowest thermal stability in a series of compounds with alkyl chains ranging from $\mathrm{C}_{12}$ to $\mathrm{C}_{18}$ (even) [9]. A comparison of the AOT series and the DBS series shows that the thermal stability is not influenced by the structure of the alkyl group. However, comparison of a previously reported study on alkylammonium-AOT catanionic surfactants with our AOT and DBS systems show that the nature of the headgroup has a greater influence on the thermal stability of these types of compounds compared to the nature of alkyl chains attached to the headgroup [24].

\subsection{DSC}

Figs. 2 and 3 represent the DSC thermograms of the heating and cooling cycles obtained for the double-chain surfactants. Fig. 4 represents the DSC thermogram for the triple-chain surfactants. The represented thermograms are for the second heating and cooling cycle at a heating rate of 10 ${ }^{\circ} \mathrm{C} / \mathrm{min}$. The reported transition temperatures, enthalpies, and entropies are the average value of multiple runs. 


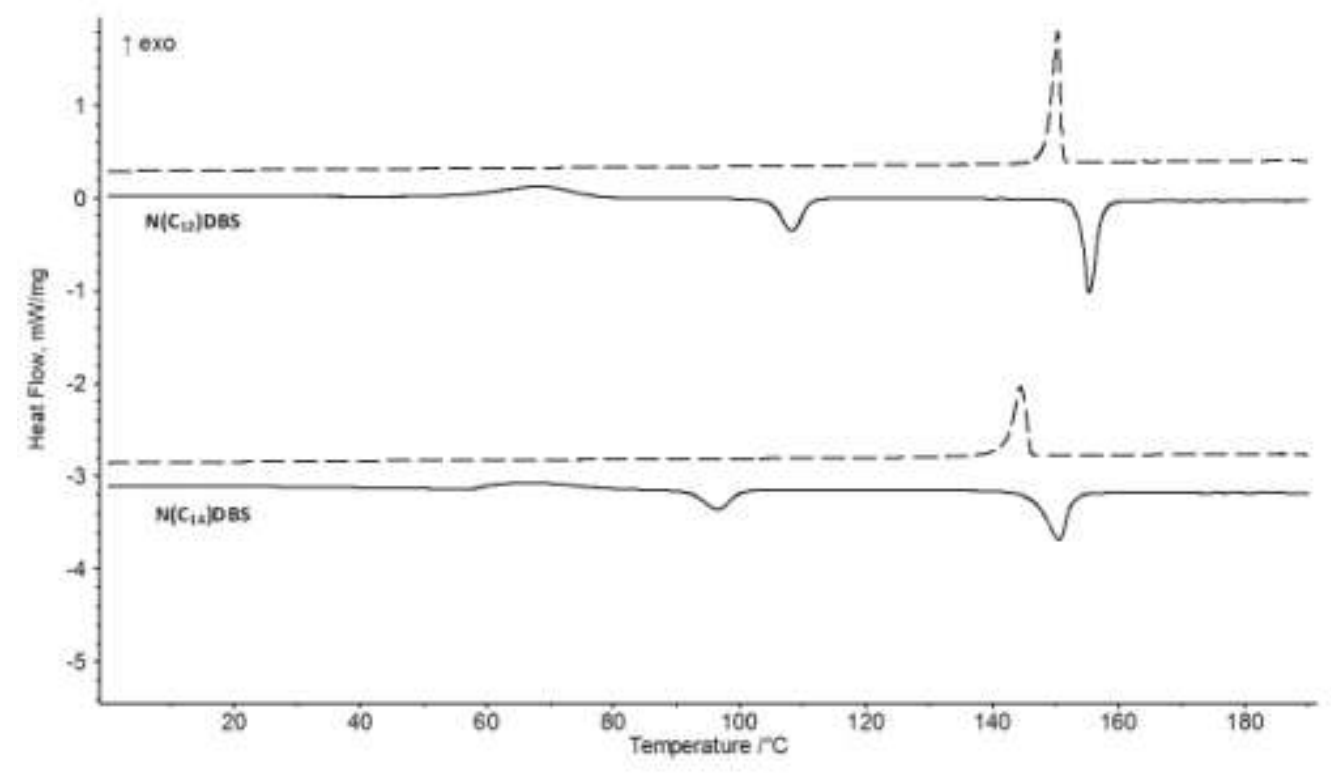

Fig. 2. DSC heating (solid) and cooling (dash) thermograms for the second heating and cooling cycle for the double-chain catanionic surfactants $\mathrm{N}\left(\mathrm{C}_{12}\right)$ DBS and $\mathrm{N}\left(\mathrm{C}_{14}\right) \mathrm{DBS}$.

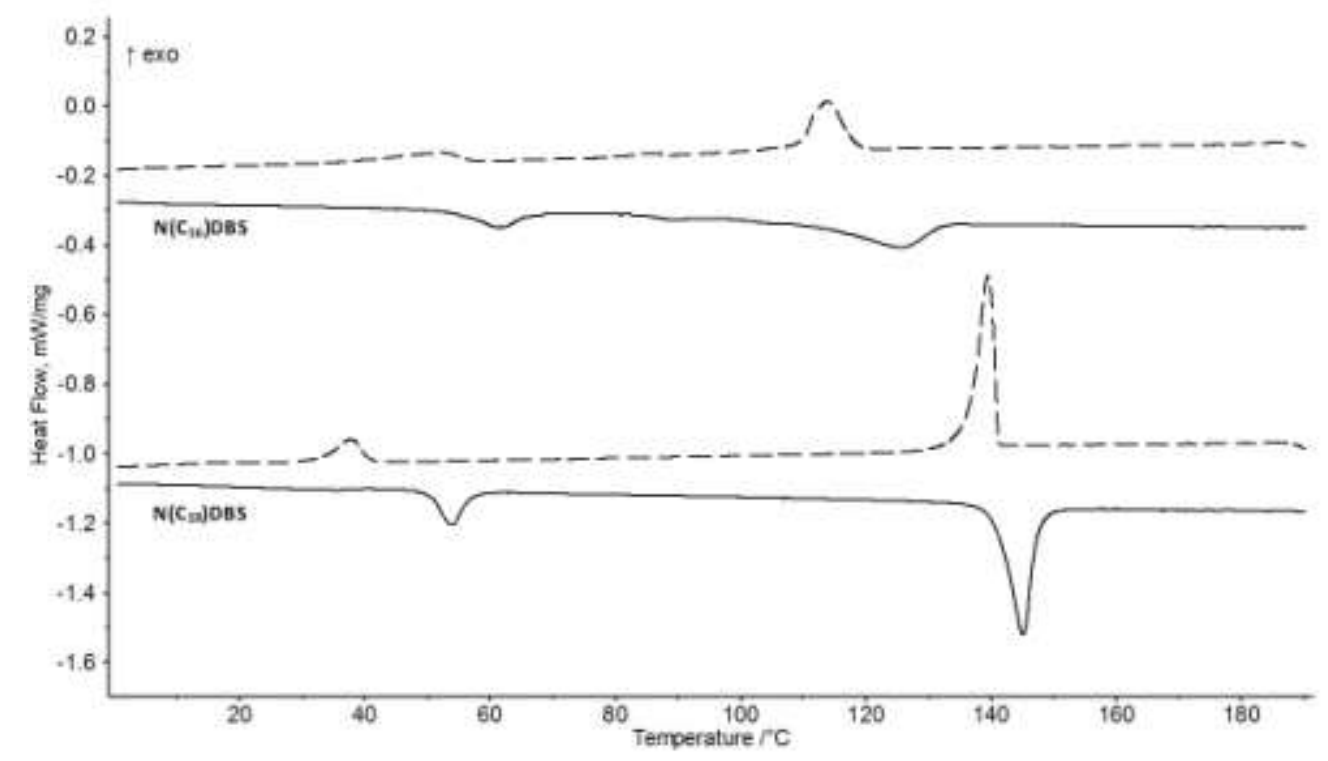

Fig. 3. DSC heating (solid) and cooling (dash) thermograms for the second heating and cooling cycle for the double-chain catanionic surfactants $\mathrm{N}\left(\mathrm{C}_{16}\right)$ DBS and $\mathrm{N}\left(\mathrm{C}_{18}\right)$ DBS. 
Above room temperature, the double-chain series has three thermal transitions upon heating except for $\mathrm{N}\left(\mathrm{C}_{18}\right)$ DBS which has only two thermal transitions. In $\mathrm{N}\left(\mathrm{C}_{12}\right)$ DBS and $\mathrm{N}\left(\mathrm{C}_{14}\right) \mathrm{DBS}$, the first transitions above room temperature (at $69.4{ }^{\circ} \mathrm{C}$ and $67.2{ }^{\circ} \mathrm{C}$, respectively) were exothermic transitions which were followed by endothermic transitions of similar magnitude at $108.3{ }^{\circ} \mathrm{C}$ and $96.6{ }^{\circ} \mathrm{C}$, respectively . However, in the cooling cycle, these transitions are absent all together. These exothermic peaks in the heating cycle may indicate the presence of cold crystallization in these compounds [25]. This phenomenon is generally observed in polymers [26]. From these exothermic transitions till the low-temperature endotherm, hexagonal columnar phase $\left(\mathrm{Col}_{\mathrm{h}}\right)$ was observed and the high-temperature endotherm corresponded to $\mathrm{Col}_{\mathrm{h}}$ to isotropic phase as corroborated with HSPLM and variable temperature XRD studies (vide infra). It is interesting to note that the enthalpy of exothermic transition decreased from $\mathrm{C}_{12}(-5.021 \mathrm{~kJ} / \mathrm{mol}$ to $\mathrm{C}_{14}(-3.845 \mathrm{~kJ} / \mathrm{mol})$. Furthermore, there are no exothermic transitions observed above $20{ }^{\circ} \mathrm{C}$ in the heating cycle of $\mathrm{N}\left(\mathrm{C}_{16}\right) \mathrm{DBS}$ and $\mathrm{N}\left(\mathrm{C}_{18}\right)$ DBS. Each of these compounds exhibited crystallization exotherm in the cooling cycle. The high-temperature exotherm in the cooling cycle was related to transformation from the isotropic phase to the $\mathrm{Col}_{\mathrm{h}}$ phase. Additionally, attempts to identify the nature of intermediate small endoderm in the case of $\mathrm{N}\left(\mathrm{C}_{16}\right) \mathrm{DBS}$ by HSPLM and XRD studies failed.

To understand the thermal transitions in the double-chain surfactants, DSC scans were run at different heating and cooling rates for $\mathrm{N}\left(\mathrm{C}_{12}\right) \mathrm{DBS}$ and $\mathrm{N}\left(\mathrm{C}_{18}\right) \mathrm{DBS}$ [27-32]. The temperature/heat data for various observed transitions for $\mathrm{N}\left(\mathrm{C}_{12}\right)$ DBS and $\mathrm{N}\left(\mathrm{C}_{18}\right)$ DBS are shown in Tables S2 and S3, respectively, in the Supplementary Materials. The corresponding DSC thermogram overlays are shown in Figs. S3 and S5, respectively, in the Supplementary Materials. With the slowest heating rate, $1{ }^{\circ} \mathrm{C} / \mathrm{min}, \mathrm{N}\left(\mathrm{C}_{12}\right)$ DBS exhibited no cold crystallization. 
However, $5^{\circ} \mathrm{C} / \mathrm{min}$ or faster heating rate exhibited cold crystallization exotherms whose peak maxima increased gradually to high temperatures $\left(54^{\circ} \mathrm{C}\right.$ to $\left.86^{\circ} \mathrm{C}\right)$. Scanning temperature rate dependence of this peak clearly suggests its out-of-equilibrium nature. Correspondingly, the melting temperature for peak B shifted from $107.0^{\circ} \mathrm{C}$ to $111.2{ }^{\circ} \mathrm{C}$ and that for $\mathrm{C}$ shifted from $154.5^{\circ} \mathrm{C}$ to $157.1{ }^{\circ} \mathrm{C}$ (Table S2 and Fig S4). The smaller dependence on scanning rate for these transitions attests for their equilibrium nature. The small shift in temperature is likely to be an effect of instrument response and thermal lags. Its isotropic transitions underwent increased supercooling from $2.64{ }^{\circ} \mathrm{C}$ to $8.22{ }^{\circ} \mathrm{C}$ with increase in scanning temperature rate. For this transition, the lowest supercooling at the lowest cooling rate is near the thermodynamic equilibrium. Although the scanning rate dependence was not studied for $\mathrm{N}\left(\mathrm{C}_{14}\right) \mathrm{DBS}$, it is very likely that the same behavior will be observed. Hence the out-of-equilibrium peaks for $\mathrm{N}\left(\mathrm{C}_{12}\right)$ DBS and $\mathrm{N}\left(\mathrm{C}_{14}\right)$ DBS are not accounted for the total enthalpy and entropy contribution. Furthermore, these transitions have no influence on the remaining transitions.

In the case of $\mathrm{N}\left(\mathrm{C}_{18}\right) \mathrm{DBS}$, melting transition was dependent on the heating rate. For example, at heating rates of 20 and $40{ }^{\circ} \mathrm{C} / \mathrm{min}$ it was $52.03{ }^{\circ} \mathrm{C}$ and $57.7^{\circ} \mathrm{C}$, respectively (Table S3). This transition underwent large degree of supercooling that was cooling rate dependent. Although no apparent trends in the transition to the isotropic phase were observed, this transition temperature was the highest at a heating rate of $40{ }^{\circ} \mathrm{C} / \mathrm{min}$ and lowest at a heating rate of 20 ${ }^{\circ} \mathrm{C} / \mathrm{min}$. It exhibited the lowest degree of supercooling $\left(1{ }^{\circ} \mathrm{C}\right)$ at a cooling rate of $20^{\circ} \mathrm{C} / \mathrm{min}$. 


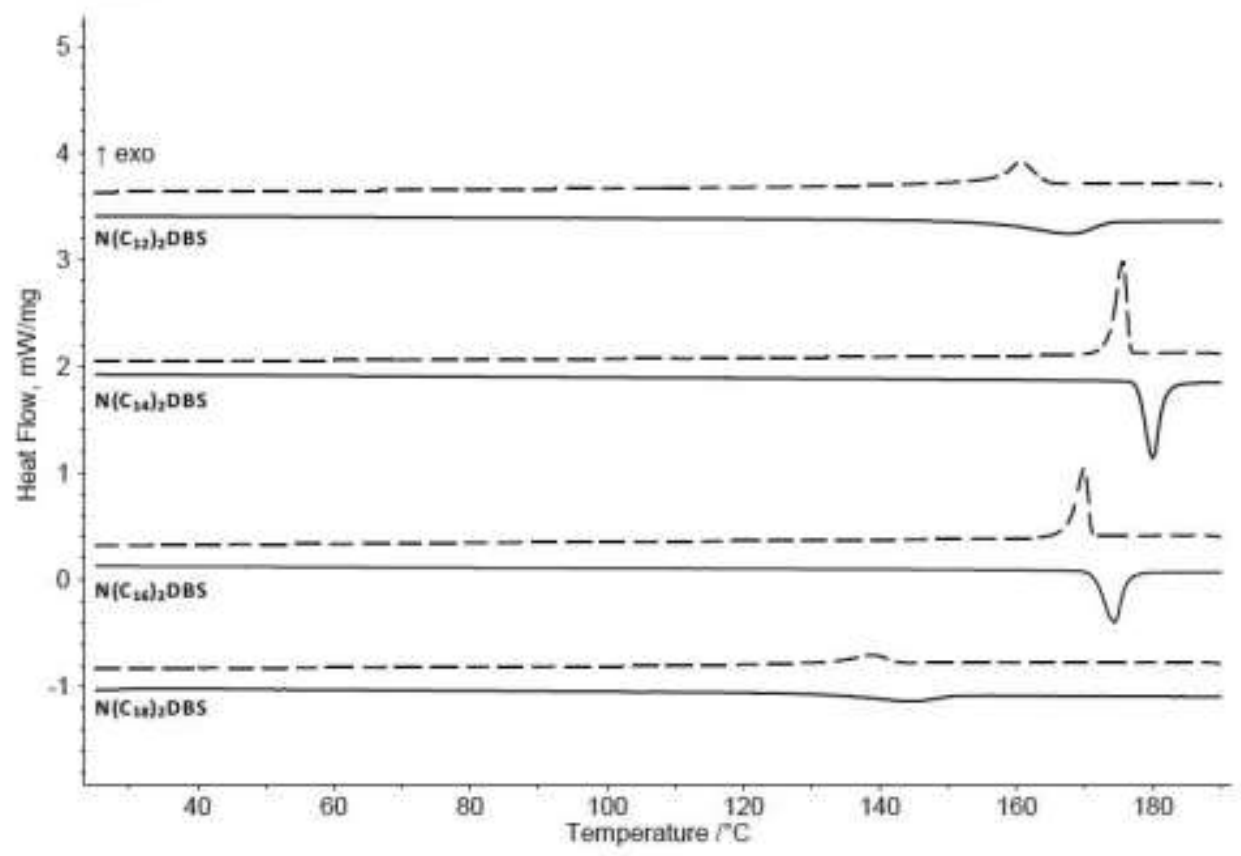

Fig. 4. DSC heating (solid) and cooling (dash) thermograms for the second heating and cooling cycle for the triple-chain catanionic surfactants.

For the triple-chain series, DSC thermograms in the heating cycles, in conjunction with HSPLM and XRD studies (vide infra), exhibited only the isotropization transitions above room temperature as seen in Fig. 4. Thsese transitions were reproduced in the cooling cycles with little supecooling suggesting that they were near thermodynamic equilibrium. Broad transition observed in $\mathrm{C}_{12}$ becomes narrow in $\mathrm{C}_{14}$ and revert to a broad transition in $\mathrm{C}_{18}$. It is noteworthy that sharper transitions have higher transition temperature and broader transitions have lower transition temperatures in both series.

Enthalpy and entropy data for heating of the double- and triple-chain catanionic surfactants are shown in Table 1. Due to the out-of-equilibrium nature of the observed transitions at $69.40{ }^{\circ} \mathrm{C}$ and $67.20{ }^{\circ} \mathrm{C}$, respectively, for $\mathrm{N}\left(\mathrm{C}_{12}\right)$ DBS and $\mathrm{N}\left(\mathrm{C}_{14}\right)$ DBS, they are not accounted for the overall enthalpy and entropy for these two compounds. 
Table 1 Transition Temperatures $(T)$, Enthalpies $(\Delta \mathrm{H})$, and approximated Entropies $(\Delta \mathrm{S})$ for the catanionic surfactants.

\begin{tabular}{|c|c|c|c|c|c|}
\hline \multicolumn{6}{|l|}{ Heating } \\
\hline Sample & $\mathrm{T}\left({ }^{\circ} \mathrm{C}\right)$ & $\Delta \mathrm{H}(\mathrm{kJ} / \mathrm{mol})$ & $\Delta \mathrm{S}(\mathrm{J} / \mathrm{K} \mathrm{mol})$ & $\begin{array}{l}\Delta \mathrm{H}_{\mathrm{ovr}} \\
(\mathrm{kJ} / \mathrm{mol})\end{array}$ & $\begin{array}{ll}\Delta \mathrm{S}_{\mathrm{ovr}} & (\mathrm{J} / \mathrm{K} \\
\mathrm{mol}) & \end{array}$ \\
\hline \multirow[t]{3}{*}{$\mathrm{N}\left(\mathrm{C}_{12}\right) \mathrm{DBS}$} & 69.40 & -5.021 & -15.18 & & \\
\hline & 108.3 & 4.660 & 12.32 & 13.373 & 32.74 \\
\hline & 155.3 & 8.713 & 20.42 & & \\
\hline \multirow[t]{3}{*}{$\mathrm{N}\left(\mathrm{C}_{14}\right) \mathrm{DBS}$} & 67.20 & -3.845 & -11.63 & & \\
\hline & 96.60 & 3.829 & 10.47 & 11.369 & 28.43 \\
\hline & 150.6 & 7.540 & 17.96 & & \\
\hline \multirow[t]{3}{*}{$\mathrm{N}\left(\mathrm{C}_{16}\right) \mathrm{DBS}$} & 61.80 & 1.108 & 3.360 & & \\
\hline & 89.70 & 0.144 & 0.400 & 4.639 & 12.49 \\
\hline & 125.8 & 3.387 & 8.730 & & \\
\hline \multirow[t]{2}{*}{$\mathrm{N}\left(\mathrm{C}_{18}\right) \mathrm{DBS}$} & 54.00 & 1.597 & 4.935 & 7.877 & 20.11 \\
\hline & 145.1 & 6.280 & 15.17 & & \\
\hline $\mathrm{N}\left(\mathrm{C}_{12}\right)_{2} \mathrm{DBS}$ & 167.8 & 5.928 & 13.77 & 5.928 & 13.77 \\
\hline $\mathrm{N}\left(\mathrm{C}_{14}\right)_{2} \mathrm{DBS}$ & 180.0 & 8.851 & 19.63 & 8.851 & 19.63 \\
\hline $\mathrm{N}\left(\mathrm{C}_{16}\right)_{2} \mathrm{DBS}$ & 174.4 & 7.644 & 17.19 & 7.644 & 17.19 \\
\hline $\mathrm{N}\left(\mathrm{C}_{18}\right)_{2} \mathrm{DBS}$ & 145.1 & 3.484 & 8.567 & 3.484 & 8.567 \\
\hline
\end{tabular}

The trend behavior of the isotropization transition in the double- and triple-chain series is shown in Figs. 5 and 6, respectively. For graphical purposes, the number of $\mathrm{CH}_{2}$ groups depicted in the figures was determined from the hydrophobic portions of the catanionic 
surfactant.

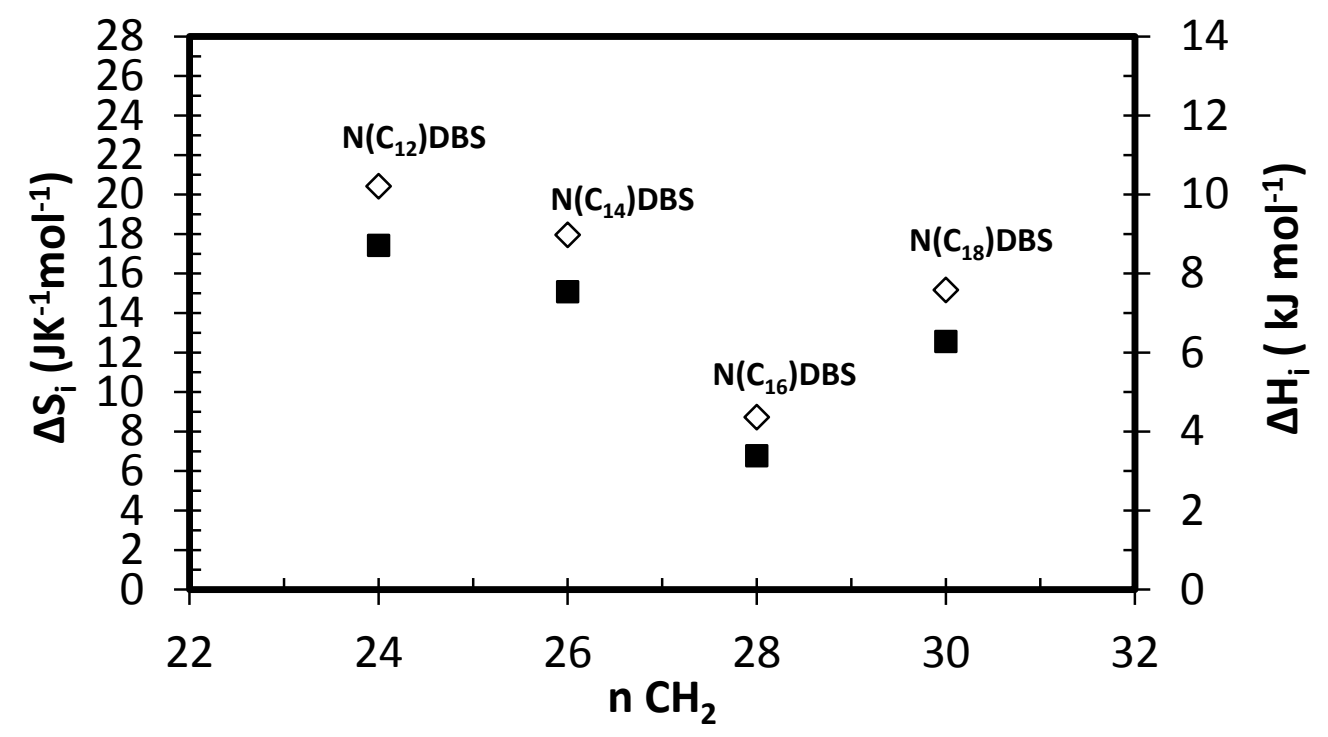

Fig. 5. $\Delta \mathrm{H}_{\mathrm{i}}(\boldsymbol{\square})$ and $\Delta \mathrm{S}_{\mathrm{i}}(\diamond)$ variation for the double-chain catanionic surfactants as a function of the number of $\mathrm{CH}_{2}$ groups in the hydrophobic chains.

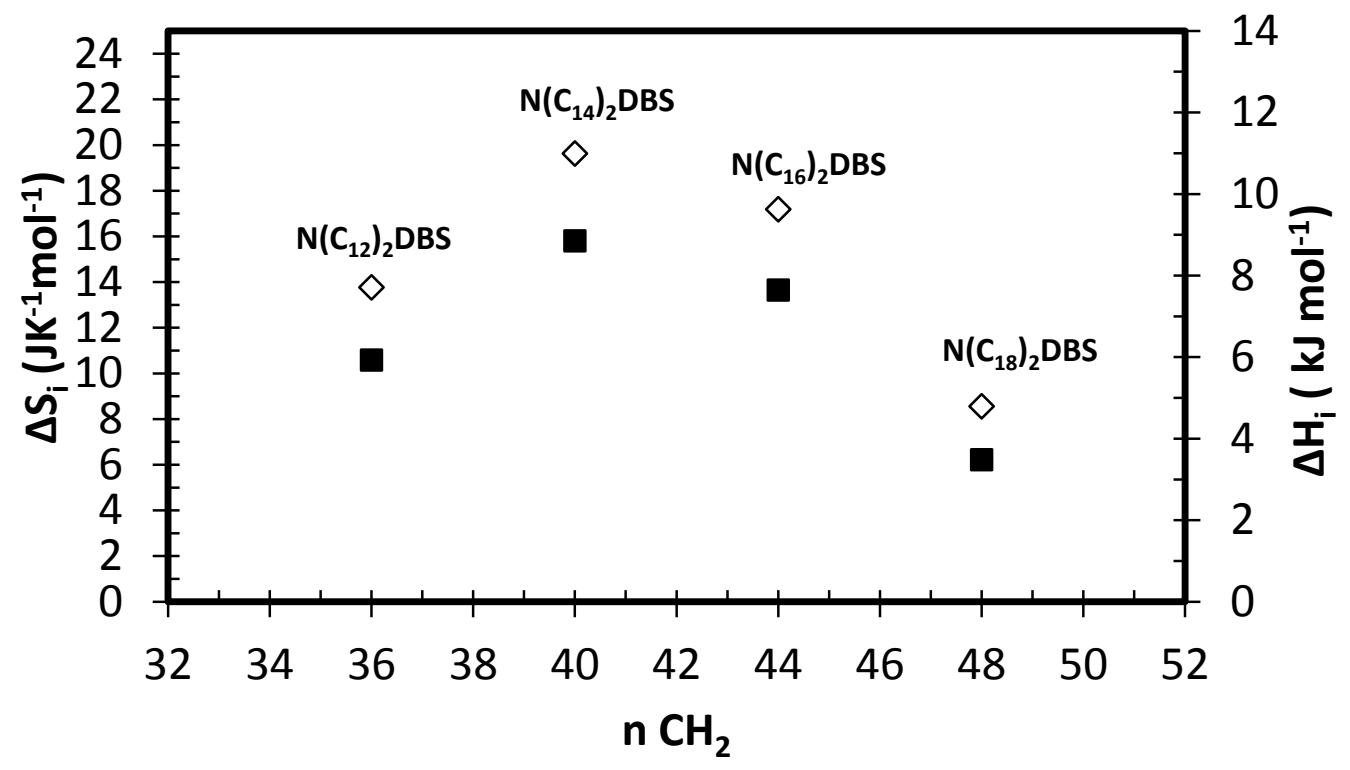

Fig. 6. $\Delta \mathrm{H}_{\mathrm{i}}(\boldsymbol{\square})$ and $\Delta \mathrm{S}_{\mathrm{i}}(\diamond)$ variation for the triple-chain catanionic surfactants as a function of the number of $\mathrm{CH}_{2}$ groups in the hydrophobic chains. 
Figs. 7 and 8, respectively show the individual transition temperatures for the double-and triplechain surfactants. These figures allow comparison of the first transition temperatures between different surfactants, along with the information pertaining to the thermotropic behavior, such as the number of mesophases present for a certain surfactant.

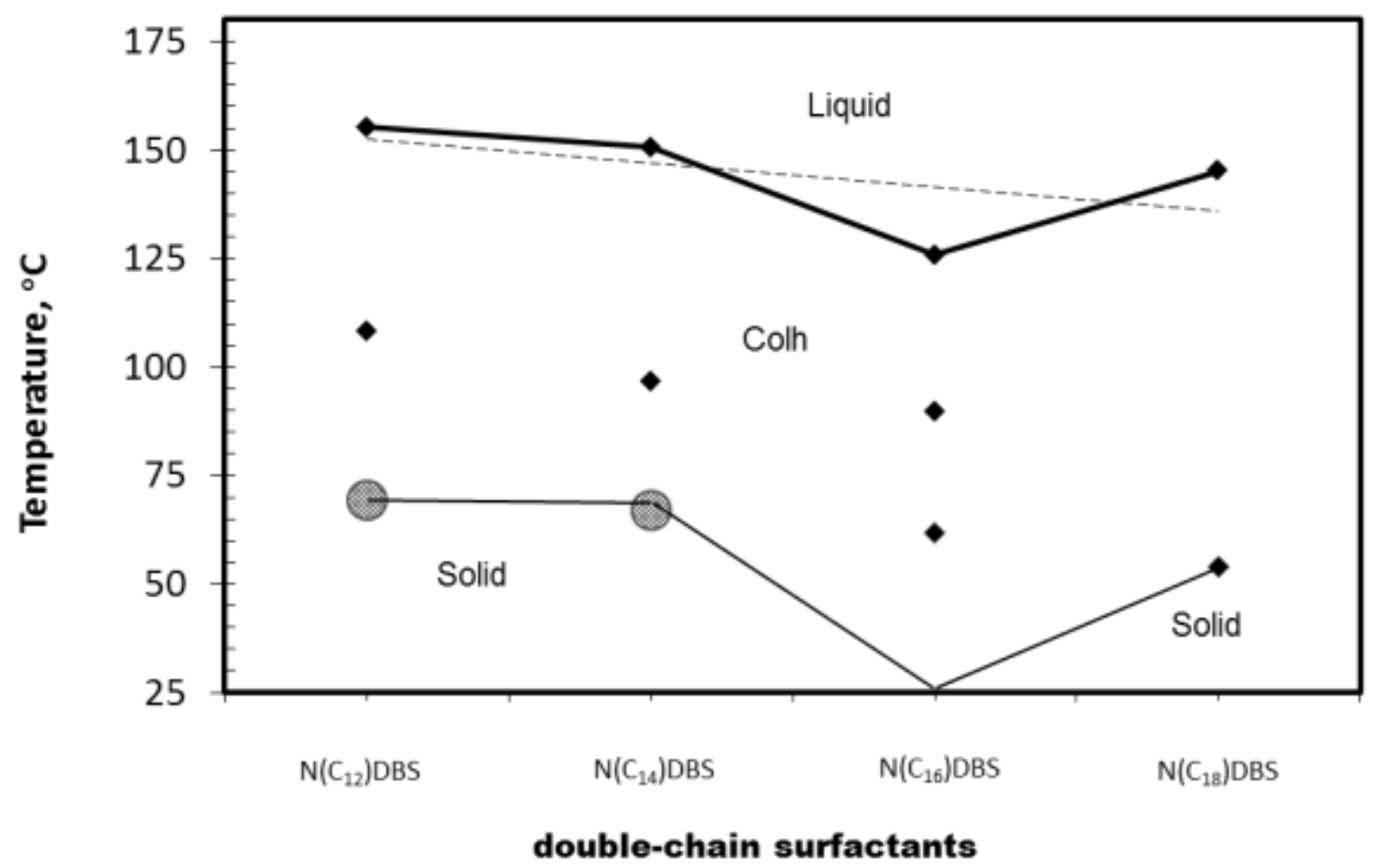

Fig. 7. Peak transition temperature chart for the double-chain surfactants. The first transition in $\mathrm{N}\left(\mathrm{C}_{12}\right)$ DBS and $\mathrm{N}\left(\mathrm{C}_{14}\right)$ DBS are given different symbol to indicate their out-ofequilibrium nature. 


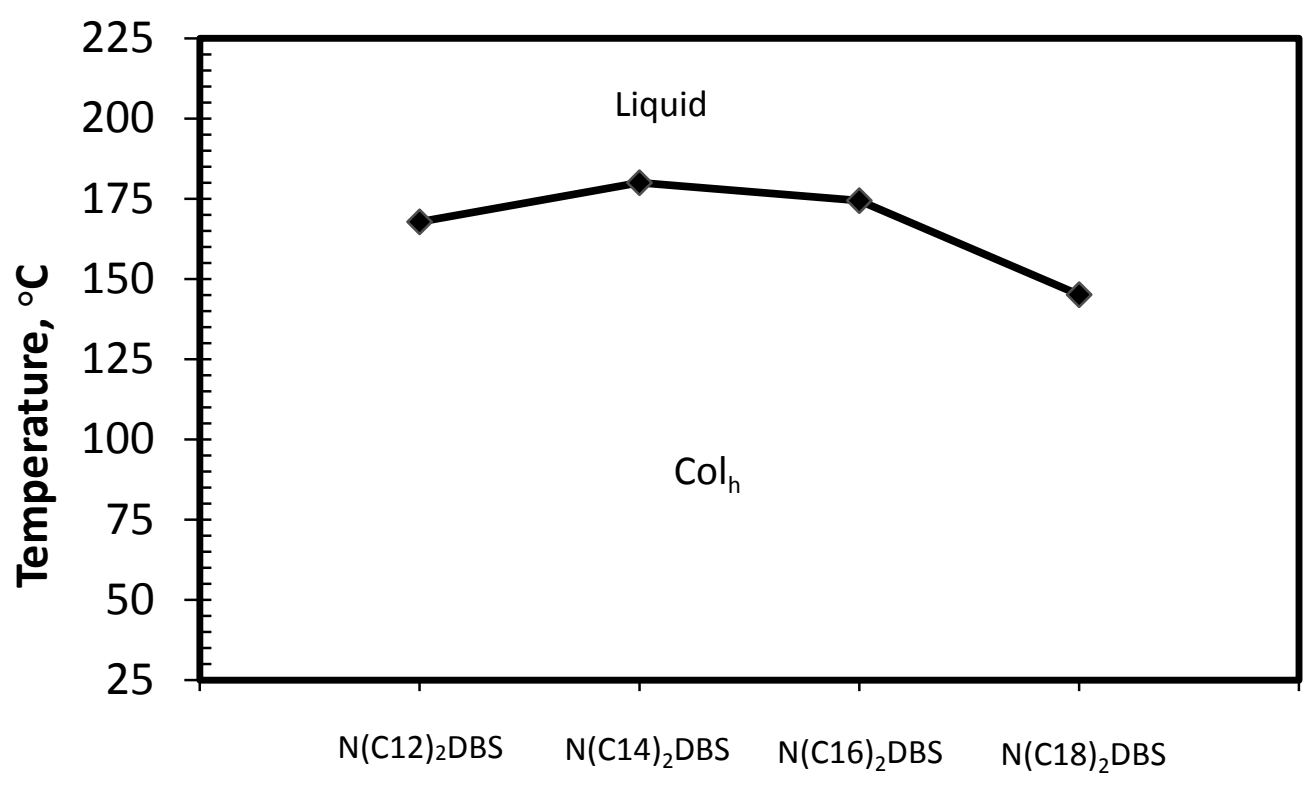

triple-chain surfactants

Fig. 8. Peak transition temperature chart for the triple-chain surfactants.

In the double-chain series, both enthalpy as well as entropy of isotropization transitions decreases from $\mathrm{C}_{12}$ to $\mathrm{C}_{16}$ and increases to $\mathrm{C}_{18}$ as shown in Table 1 and Fig. 5 . It is noteworthy that the first transition temperature (not considering the out-of-equilibrium transitions in $\mathrm{C}_{12}$ and $\mathrm{C}_{14}$ ) in $\mathrm{C}_{12}-\mathrm{C}_{18}$ (even) decreases with increase in the alkyl chain length (Fig. 7). The decrease in $\Delta \mathrm{H}_{\mathrm{i}}, \Delta \mathrm{S}_{\mathrm{i}}$, and $\mathrm{T}_{\mathrm{i}}$ with increasing chain length has been previously reported [24]. The $\mathrm{T}_{\mathrm{i}}$ for $\mathrm{N}\left(\mathrm{C}_{16}\right)$ DBS can be thought of as falling off of a decreasing trend line (dotted line in Fig. 7). $\mathrm{N}\left(\mathrm{C}_{16}\right)$ DBS may represent a compromise between the headgroup interactions and chain interactions where the packing restriction of the chain influences the headgroup interactions and dramatically lowers the $T_{i}$. Note here that catanionic surfactant derived from hexadecyltrimethylammonium bromide with octylbenzenesulfonate, $\mathrm{N}\left(\mathrm{C}_{16}\right) \mathrm{OBS}$, exists as crystalline materials until $194{ }^{\circ} \mathrm{C}$ [12]. Benzene ring in the DBS portion can be considered contributing to the alkyl chain length by 4 to 5 carbons $[33,34]$. Therefore, DBS can be 
considered to have an effective chain length of 16 methylene groups instead of just 12 . Hence, the chain length-asymmetry in this series can be considered decreasing from $\mathrm{N}\left(\mathrm{C}_{12}\right)$ DBS to $\mathrm{N}\left(\mathrm{C}_{16}\right)$ DBS and increasing to $\mathrm{N}\left(\mathrm{C}_{18}\right)$ DBS. This observation suggests that the enthalpy and entropy of isotropization are higher for more asymmetric compounds than to symmetric ones. A similar behavior was reported for a series of alkyl-trimethylammonium alkylsulfonates with varying degree of chain length-asymmetry. Greater stability for the more asymmetric compounds in these smectic LC forming systems was thought to be as a result of the effective interdigitation of alkyl chains [35]. The above observations, strongly suggest that the increase in alkyl chain length and symmetry reduce molecular ordering and crystallinity in catanionic surfactants. The substantially lower $\mathrm{T}_{\mathrm{i}}$ for $\mathrm{N}\left(\mathrm{C}_{16}\right)$ DBS compared to that of the $\mathrm{N}\left(\mathrm{C}_{16}\right)$ OBS may also be in part due to the presence of small amount of isomeric DBS (dodecyl group in the ortho position) in the commercial SDBS used for the preparation of all of our samples. Although SDBS was subjected to purification to enhance the isomeric purity, $100 \%$ isomeric purity was not achieved.

\subsection{HSPLM.}

This behavior in molecular ordering can be seen in the HSPLM photomicrographs of the doublechain and triple-chain catanionic surfactants at room temperature shown in Fig. 9. 


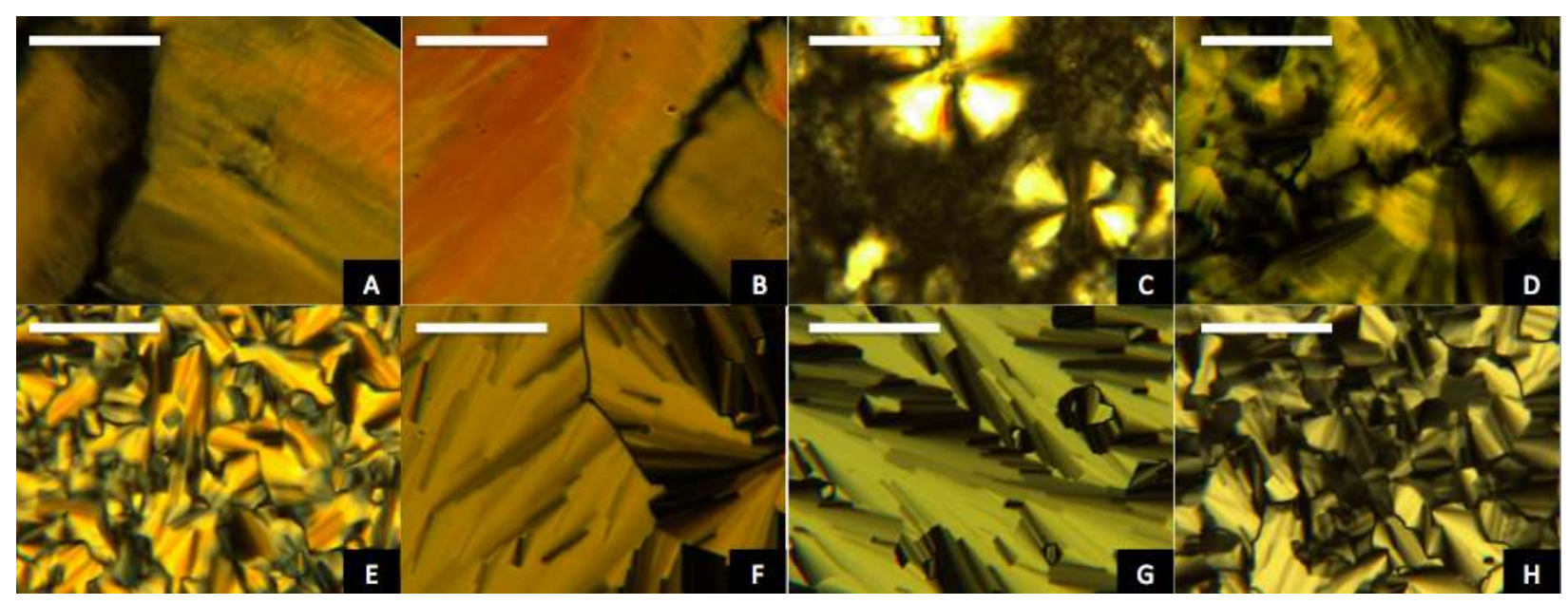

Fig. 9. HSPLM Photomicrographs (crossed polarizers) of the catanionic surfactants at $24{ }^{\circ} \mathrm{C}$ and 50x magnification. (A) $\mathrm{N}\left(\mathrm{C}_{12}\right) \mathrm{DBS}$; (B) $\mathrm{N}\left(\mathrm{C}_{14}\right) \mathrm{DBS}$; (C) $\mathrm{N}\left(\mathrm{C}_{16}\right) \mathrm{DBS}$; (D) $\mathrm{N}\left(\mathrm{C}_{18}\right) \mathrm{DBS}$; (E) $\mathrm{N}\left(\mathrm{C}_{12}\right)_{2} \mathrm{DBS} ;(\mathrm{F}) \mathrm{N}\left(\mathrm{C}_{14}\right)_{2} \mathrm{DBS} ;(\mathrm{G}) \mathrm{N}\left(\mathrm{C}_{16}\right)_{2} \mathrm{DBS} ;(\mathrm{H}) \mathrm{N}\left(\mathrm{C}_{18}\right)_{2} \mathrm{DBS}$. Scale bar $=10 \mu \mathrm{m}$.

An examination of the spherulitic morphologies of the double-chain series in Figs. 9A-D shows that $\mathrm{N}\left(\mathrm{C}_{16}\right)$ DBS (Fig. 9C) has vaguely formed spherulites, which supports the above argument of molecular ordering and chain length. The magnitude of the $\Delta \mathrm{H}_{\mathrm{i}}$ value also is in agreement with this observation where $\mathrm{N}\left(\mathrm{C}_{12}\right) \mathrm{DBS}$ with a $\Delta \mathrm{H}_{\mathrm{i}}$ of $8.71 \mathrm{~kJ} / \mathrm{mol}$ and $\mathrm{N}\left(\mathrm{C}_{14}\right) \mathrm{DBS}$ with $\Delta \mathrm{H}_{\mathrm{i}}$ of $7.54 \mathrm{~kJ} / \mathrm{mol}$ show crystalline textures at $24{ }^{\circ} \mathrm{C}$ and are well defined as shown in Figs. 9A and 9B, respectively. $\Delta \mathrm{H}_{\mathrm{i}}$ for $\mathrm{N}\left(\mathrm{C}_{16}\right) \mathrm{DBS}$ is $4.62 \mathrm{~kJ} / \mathrm{mol}$ which is the lowest in that series and was least ordered.

In the triple-chain series, $\mathrm{T}_{\mathrm{i}}, \Delta \mathrm{H}_{\mathrm{i}}$, and $\Delta \mathrm{S}_{\mathrm{i}}$ increases from $\mathrm{C}_{12}$ to $\mathrm{C}_{14}$ and decreases from $\mathrm{C}_{14}$ to $\mathrm{C}_{18}$ (Table 1 and Fig. 8). This trend may represent an increase in Van der Waals interactions as the chain length is extended from $\mathrm{C}_{12}$ to $\mathrm{C}_{14}$. However, conformational disorder may increase as the chain gets larger, thus diminishing the effect of Van der Waals interaction between the chains. Here too the magnitude of $\Delta \mathrm{H}_{\mathrm{i}}$ and $\Delta \mathrm{S}_{\mathrm{i}}$ can be related to the molecular ordering which is 
in agreement with the HSPLM results (Fig. 9E-H). The spherulitic morphology of $\mathrm{N}\left(\mathrm{C}_{14}\right)_{2} \mathrm{DBS}$ (Fig. 9F) and $\mathrm{N}\left(\mathrm{C}_{16}\right)_{2} \mathrm{DBS}$ (Fig. 9G) appears more clearly defined and have higher $\Delta \mathrm{H}_{\mathrm{i}}$ and $\Delta \mathrm{S}_{\mathrm{i}}$ compared to $\mathrm{N}\left(\mathrm{C}_{12}\right)_{2} \mathrm{DBS}$ and $\mathrm{N}\left(\mathrm{C}_{18}\right)_{2} \mathrm{DBS}$. A similar trend was observed for the catanionic surfactants $\mathrm{N}\left(\mathrm{C}_{\mathrm{n}}\right)_{2} \mathrm{AOT}$, where $\mathrm{n}=12-18$ (even), where $\mathrm{C}_{14}$ had the highest $\Delta \mathrm{H}_{\mathrm{i}}$ and $\Delta \mathrm{S}_{\mathrm{i}}$ [9]. Furthermore, catanionic surfactant derived from dimethyldioctadecylammonium bromide and octylbenzenesulfonate, $\mathrm{N}\left(\mathrm{C}_{18}\right)_{2} \mathrm{OBS}$, exist as a crystalline material till $59{ }^{\circ} \mathrm{C}[11]$ in contrast to $\mathrm{N}\left(\mathrm{C}_{18}\right)_{2} \mathrm{DBS}$ which exists as a liquid crystal at $24{ }^{\circ} \mathrm{C}$. This difference cannot be assigned solely due to the chain length effect. Isomeric DBS from the commercial sample may also be influencing the solid state packing and the mesomorphic behavior in $\mathrm{N}\left(\mathrm{C}_{18}\right)_{2} \mathrm{DBS}$ as in case of $\mathrm{N}\left(\mathrm{C}_{16}\right)$ DBS mentioned earlier. It is noteworthy that additional alkyl chain in $\mathrm{N}\left(\mathrm{C}_{18}\right)_{2} \mathrm{OBS}$ favors the formation of mesophases at a lower temperature. This also suggests reduced headgroup interaction as the alkyl chain length and number are increased.

The corresponding mesophase textures after the first (out-of-equilibrium) and second transitions in $\mathrm{N}\left(\mathrm{C}_{12}\right)$ DBS and $\mathrm{N}\left(\mathrm{C}_{14}\right)$ DBS are shown in Fig. S7 in the Supplementary Materials. Comparison of the mesophases in Figs. S7A and S7B, respectively, to Figs. 9A and 9B show a crystal to liquid crystal transition. 


\subsection{X-Ray Diffraction}

Representative XRD patterns at $\mathrm{T}=30{ }^{\circ} \mathrm{C}$ of $\mathrm{N}\left(\mathrm{C}_{\mathrm{n}}\right)$ DBS and $\mathrm{N}\left(\mathrm{C}_{\mathrm{n}}\right)_{2} \mathrm{DBS}$ acquired using the Rigaku Screen machine are presented in Fig. 10A-D. All patterns show relatively intense

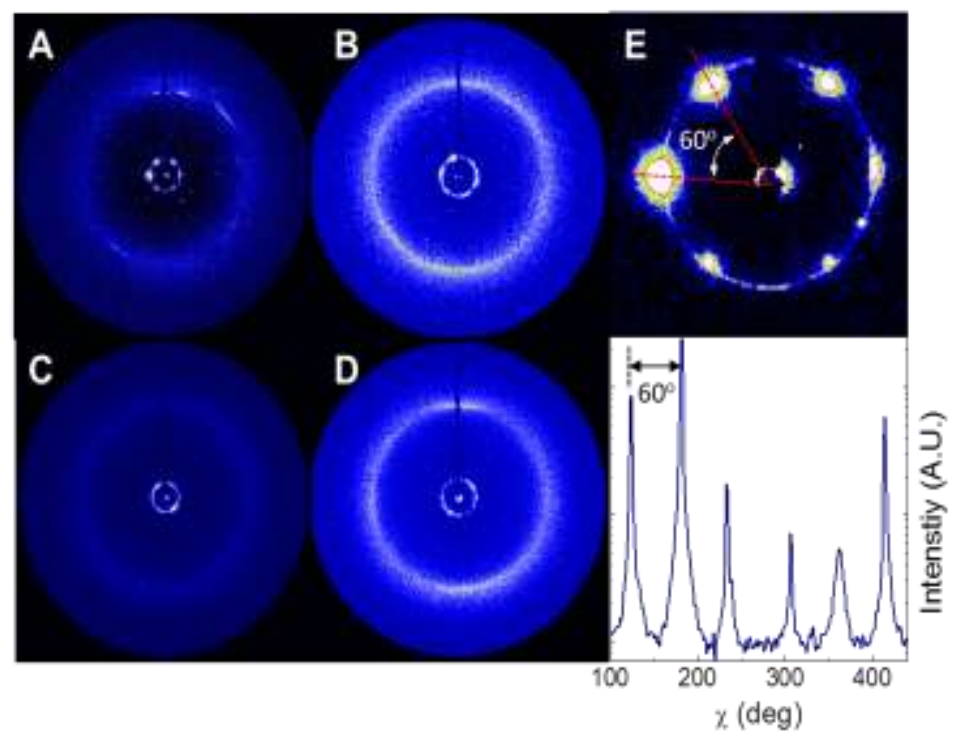

Fig. 10. $\mathrm{X}$-ray diffraction patterns at $\sim 30^{\circ} \mathrm{C}$ for $(A) \mathrm{N}\left(\mathrm{C}_{12}\right) \mathrm{DBS}$, phase reminiscent of similar (B) $\mathrm{N}\left(\mathrm{C}_{14}\right)_{2} \mathrm{DBS}$, (C) $\mathrm{N}\left(\mathrm{C}_{16}\right) \mathrm{DBS}$, (D) $\mathrm{N}\left(\mathrm{C}_{16}\right)_{2} \mathrm{DBS}$, and (E) expanded view of the small angle reflection at $\sim 27.4^{\circ} \mathrm{C}$ (upper panel) with corresponding $\chi$-scan, showing radially integrated intensity at small angle plotted against the polar angle $\chi$ in the scattering plane (lower panel). The integrated intensities for (A), (B), (C), and (D) may be found in Fig. S14 in the Supplementary Materials. scattering in the small-angle

region, and weak scattering

in the wide-angle region. Six

diffraction spots $\sim 60^{\circ}$ apart

located at $d=27.4 \AA$ for

double-chain $\quad \mathrm{N}\left(\mathrm{C}_{12}\right) \mathrm{DBS}$

(Fig. 10E) confirm the hexagonal columnar $\left(\mathrm{Col}_{\mathrm{h}}\right)$ molecular organization by cationic surfactants with bis(2-ethylhexyl)sodium sulfosuccinate

$[9,24,36]$. The wide- angle peak centered at $\sim 4.8 \AA$ corresponds to the average transverse separation between the molecules. The lattice parameter, $a$, is related to the position $(d)$ of the scattering reflections by $\frac{1}{d^{2}}=\frac{4}{3 a^{2}} \sqrt{h^{2}+k^{2}+h k}$ where $h$ and $k$ are the Miller indices. The most intense peak corresponds to the (1 0$)$ scattering planes. Lattice parameter $a$ depends on the number of carbons, $n$ in the chains. For both series of compounds, (i.e. double- and triplechained), $a$ increases with $n$ which is expected. Lattice parameter increases linearly from $31.6 \AA$ $(n=12)$ to $34.9 \AA(n=18)$ for the double chain compound, $\mathrm{N}\left(\mathrm{C}_{n}\right) \mathrm{DBS}$, and from $24.7 \AA(n=12)$ 
to $27.9 \AA(n=18)$ for triple chain $\mathrm{N}\left(\mathrm{C}_{\mathrm{n}}\right)_{2} \mathrm{DBS}$, which means that the asymmetry in the hydrocarbon chain length influences the packing of molecules along the column axis. This asymmetry arises when $n$ is greater than the number of hydrocarbon chains of DBS $(n>12)$. The chain length's effect on $a$ is summarized in Table 2.

TABLE 2 Lattice parameter, $a$ and peak positions $d$ at different chain length, $n$.

\begin{tabular}{llll}
\hline \hline & $n$ & $d(\AA)$ & $a(\AA)$ \\
\hline $\mathrm{N}\left(\mathrm{C}_{n}\right) \mathrm{DBS}$ & 12 & 27.4 & 31.6 \\
& 14 & 28.2 & 32.6 \\
& 16 & 29.9 & 34.5 \\
& 18 & 30.2 & 34.9 \\
\hline $\mathrm{N}\left(\mathrm{C}_{n}\right)_{2} \mathrm{DBS}$ & 12 & 21.4 & 24.7 \\
& 14 & 22.0 & 25.4 \\
& 16 & 23.0 & 26.6 \\
& 18 & 24.2 & 27.9 \\
\hline \hline
\end{tabular}

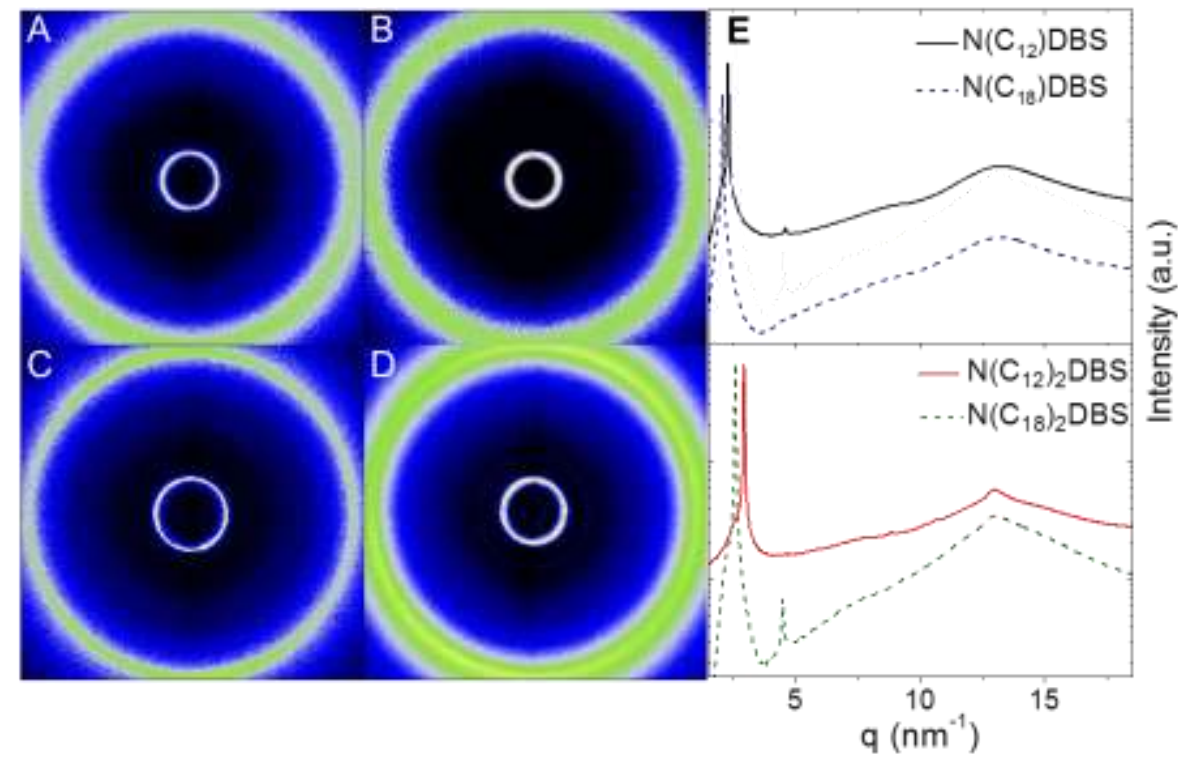

Fig. 11. XRD patterns for (A) $\mathrm{N}\left(\mathrm{C}_{12}\right) \mathrm{DBS}$; (B) $\mathrm{N}\left(\mathrm{C}_{18}\right) \mathrm{DBS}$; (C) $\mathrm{N}\left(\mathrm{C}_{12}\right)_{2} \mathrm{DBS}$, and (D) $\mathrm{N}\left(\mathrm{C}_{18}\right)_{2} \mathrm{DBS}$ measured at X27C NSLS, BNL. (E) Corresponding integrated intensities.
Note that the lattice parameter is smaller for the triple chain compound of the same number of carbons. For example, $\mathrm{N}\left(\mathrm{C}_{18}\right)_{2} \mathrm{DBS}$ has $a=$ $27.9 \AA$ while for $\mathrm{N}\left(\mathrm{C}_{18}\right) \mathrm{DBS}, a=34.9$ $\AA$. This shows that the 
molecular organization is also influenced by the number of radial chains in columns which is required for efficient space filling. Except for $\mathrm{N}\left(\mathrm{C}_{12}\right) \mathrm{DBS}$ and $\mathrm{N}\left(\mathrm{C}_{18}\right)_{2} \mathrm{DBS}$, no other intermediate reflections are observed. Very faint reflections in the intermediate region at $d \sim 13.7$ $\AA$ for $\mathrm{N}\left(\mathrm{C}_{12}\right) \mathrm{DBS}$ and at $\sim 14.0 \AA$ and $\sim 12.1 \AA$ for $\mathrm{N}\left(\mathrm{C}_{18}\right)_{2} \mathrm{DBS}$ were observed (Fig. 10E). The weak peaks for $\mathrm{N}\left(\mathrm{C}_{18}\right)_{2} \mathrm{DBS}$ are notably the $\mathrm{d} / \sqrt{3}$ and $\mathrm{d} / 2$ reflections arising from the $\left(\begin{array}{ll}1 & 1\end{array}\right)$ and (2 0 ) planes of 2D hexagonal lattice. Extended exposure however, barely improved the intensity above the noise level.

To confirm these diffraction peaks, synchrotron measurements on the compounds with $n=12$ and 18 were made. XRD patterns are presented in Fig. 11 and their corresponding integrated intensity vs. scattering vector magnitude $q$ scans are shown in Fig. 11E.

For triple-chain $\mathrm{N}\left(\mathrm{C}_{18}\right)_{2} \mathrm{DBS}$, the hexagonal columnar phase $\left(\mathrm{Col}_{\mathrm{h}}\right)$ is confirmed (Fig. 11D). In addition to the small-angle reflection centered at $d=24.2 \AA$, there are two additional reflections at $d=14.0 \AA$ and $12.1 \AA$ marked in Fig. 11E consistent with the XRD results from the Screen Machine. The scattering pattern of $\mathrm{N}\left(\mathrm{C}_{12}\right)_{2} \mathrm{DBS}$ shown in Fig. $11 \mathrm{C}$ also exhibits the $\mathrm{Col}_{\mathrm{h}}$ phase, however the reflections from the (1 1 1) and (2 0$)$ planes are absent. The most intense small angle reflection occurs at $\mathrm{d}=21.4 \AA$, with additional reflections at $d=8.1 \AA$, $7.1 \AA$, and $5.9 \AA$ A. These additional reflections, corresponding to $d / \sqrt{7}, d / 3$, and $d / \sqrt{13}$, are identified as (2 1), (3 0), and (3 1) reflections of the 2D hexagonal lattice.

The XRD pattern for $\mathrm{N}\left(\mathrm{C}_{12}\right)$ DBS shown in Fig. 11A has the most intense reflection located at $d=27.4 \AA$ consistent with previous results shown in Fig. 10A. Additional significant reflection at $d=13.7 \AA$ is clearly observed which correspond to $(20)$ plane of $2 \mathrm{D}$ hexagonal lattice. The small angle reflection at $d=30.2 \AA$ for $\mathrm{N}\left(\mathrm{C}_{18}\right) \mathrm{DBS}$ in Fig. 11B appear to be wider with than expected for hexagonal packing of columns with full-width-half-maximum (FWHM) 
of $\sim 0.05006 \AA^{-1}$. This can be interpreted as a nematic phase especially in the absence of second order reflection. Another possibility is that there is secondary peak/reflection very close to the most intense peak which is not fully resolved. To rule out this possibility, the sample was heated to isotropic phase then cooled very slowly at the rate of $0.3{ }^{\circ} \mathrm{C} / \mathrm{min}$ to ambient temperature (26 ${ }^{\circ} \mathrm{C}$ ). Instead of a single wide peak, two fully resolved peaks at $d_{1}=34.4$ and $d_{2}=29.5 \AA$ were observed (Fig. 12). Additional weak reflections appear at $d \sim 19.9,18.7$ and $17.2 \AA$. The reflection at $19.9 \AA$ is at a ratio of $\sqrt{3}$ of $d_{1}$ and the peak at $17.2 \AA$ is about $d_{1} / 2$ or $d_{2} / \sqrt{3}$, while the peak at $18.7 \AA$ cannot be indexed with any of the two main reflections $\left(d_{1}\right.$ and $\left.d_{2}\right)$. It appears that the phase is a crystalline phase and not the expected liquid crystalline $\mathrm{Col}_{\mathrm{h}}$ phase.

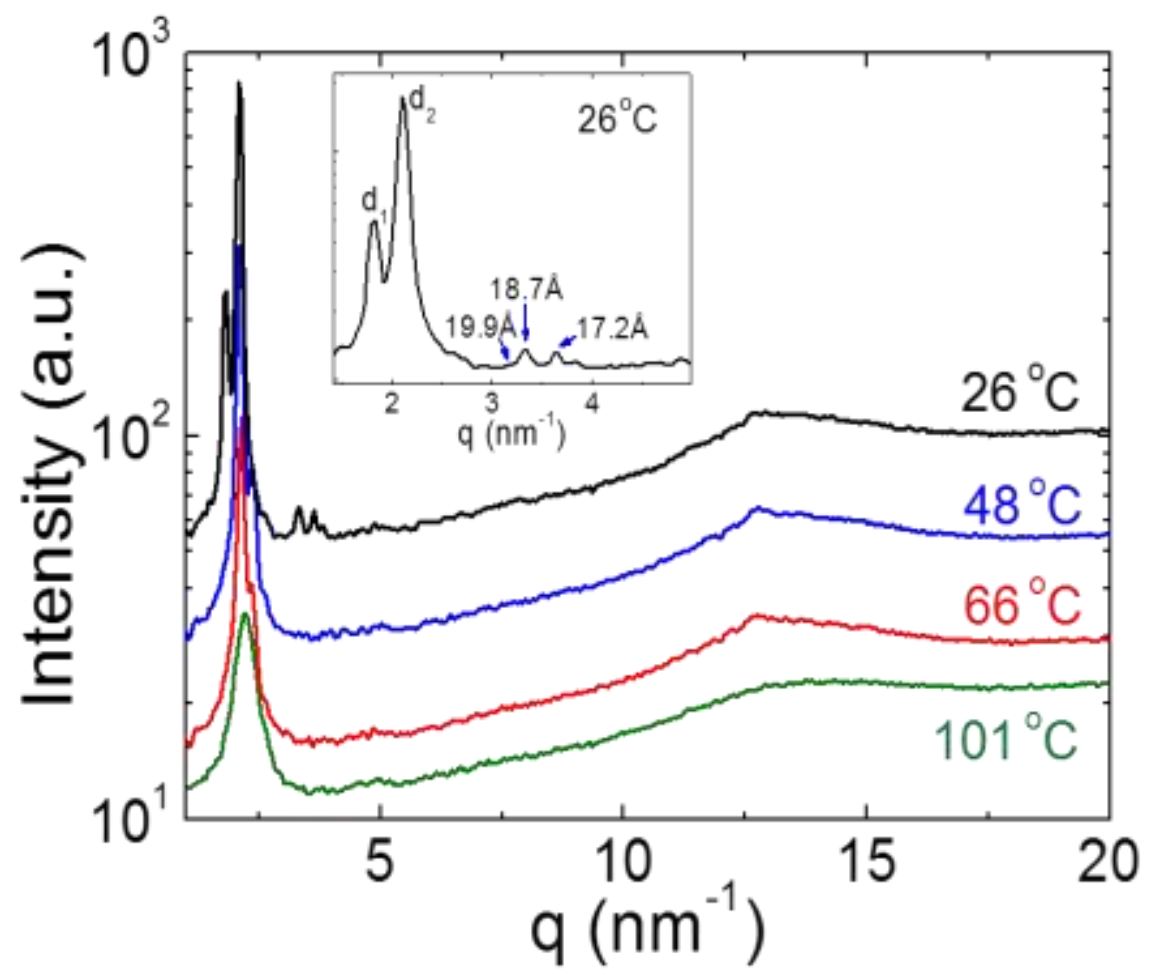

Fig. 12. Integrated intensity profiles at various temperatures for $\mathrm{NC}\left({ }_{18}\right)$ DBS.The small $q$-range scattering peaks at $26{ }^{\circ} \mathrm{C}$ are marked in the inset. 


\subsubsection{Effect of Temperature}

With the goal of understanding how the complex $\mathrm{Col}_{\mathrm{h}}$ structure for $\mathrm{N}\left(\mathrm{C}_{18}\right) \mathrm{DBS}$ is formed, XRD scans were recorded while slow cooling $\left(0.3{ }^{\circ} \mathrm{C} / \mathrm{min}\right)$ from isotropic phase. Results, shown in Fig. 12 however, did not reveal significant information other than the gradual splitting of the $28.3 \AA$ reflection at $101{ }^{\circ} \mathrm{C}$ as the sample is cooled.

Interestingly, the DSC scans (Fig. 2) for $\mathrm{N}\left(\mathrm{C}_{12}\right) \mathrm{DBS}$ and $\mathrm{N}\left(\mathrm{C}_{14}\right)$ DBS on heating suggest cold crystallization characterized by an appearance of exothermic transition followed by endothermic transition. In order to verify the structures through these transitions, XRD measurements were made on these samples during the heating cycle $\left(3{ }^{\circ} \mathrm{C} / \mathrm{min}\right)$. Both show crystalline pattern at room temperature $\left(24.6{ }^{\circ} \mathrm{C}\right)$. For brevity, only patterns for $\mathrm{C}_{12}$ during the heating cycle are shown in Fig. 13.
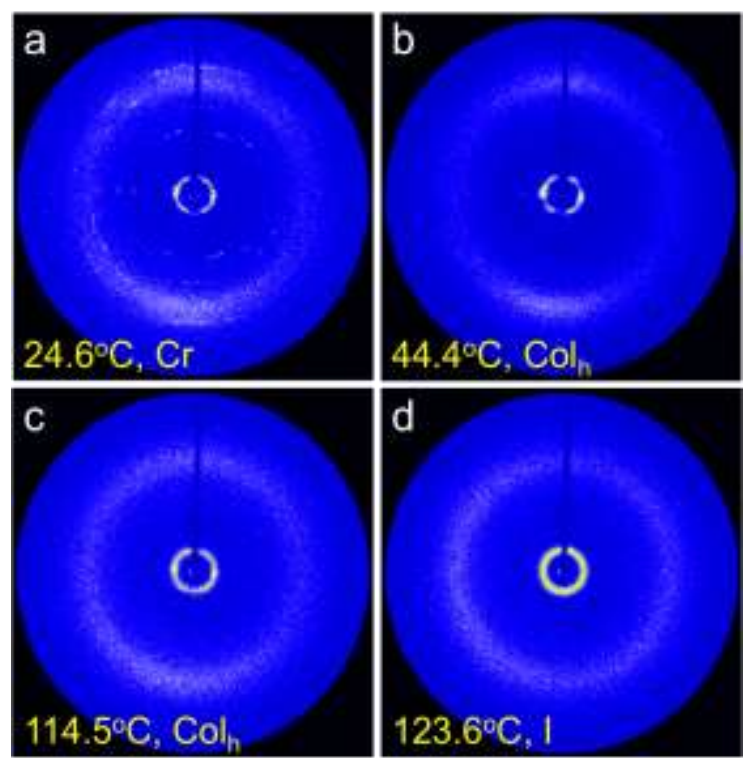

Fig. 13. XRD patterns for $\mathrm{N}\left(\mathrm{C}_{12}\right) \mathrm{DBS}$ during heating cycle. 
The crystalline phase (Fig.13a), transforms into $\mathrm{Col}_{\mathrm{h}}$ phase at $\sim 40{ }^{\circ} \mathrm{C}$, and isotropic phase ${ }^{4}$ at approximately $115{ }^{\circ} \mathrm{C}$. Two patterns for $\mathrm{Col}_{\mathrm{h}}$ at $\mathrm{T}=44.4{ }^{\circ} \mathrm{C}$ and at the temperature just below isotropic transition $\left(\mathrm{T}=114{ }^{\circ} \mathrm{C}\right)$ are depicted in Figs. 13b and 13c, respectively. The wide-angle reflections around $4.7 \AA$ show preferred orientation (two arcs along the vertical) at $44.4{ }^{\circ} \mathrm{C}$. These arcs become nearly a single diffuse ring $\left(\mathrm{T}=114{ }^{\circ} \mathrm{C}\right)$ as temperature was raised. Between the endothermic transition and isotropic phase, only the $\mathrm{Col}_{\mathrm{h}}$ phase was observed. Temperature dependence of the lattice spacing shows decreasing $d$ with increasing temperature (Fig. 14), both for $\mathrm{C}_{12}$ and $\mathrm{C}_{14}$, which indicates that the columns are closely packed. Intuitively, $d$ should increase when temperature increases, as the column become less correlated. Additional variable temperature XRD data is included in the Supplementary Materials.

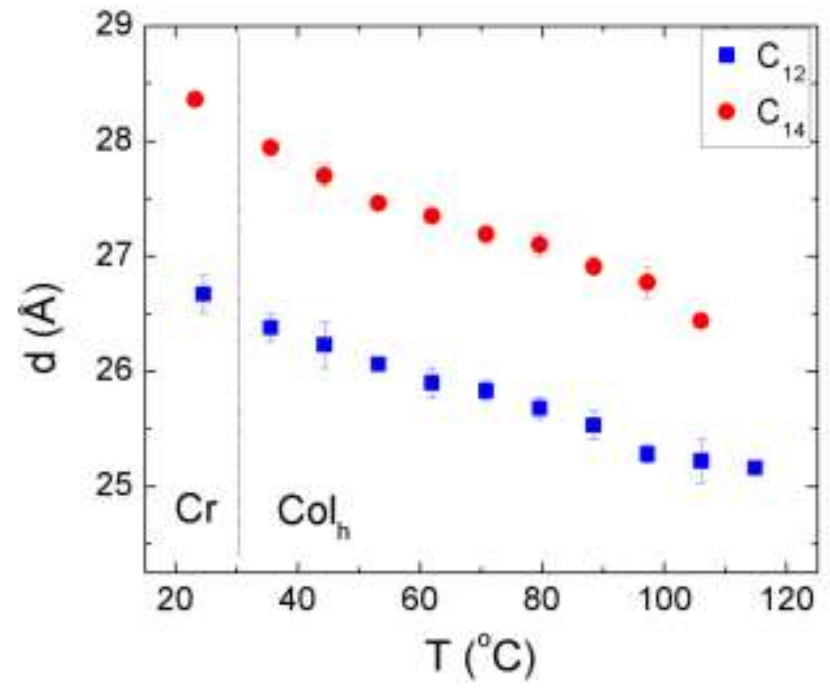

Fig. 14. Temperature dependence of $d$ for $\mathrm{N}\left(\mathrm{C}_{12}\right)$ DBS and $\mathrm{N}\left(\mathrm{C}_{14}\right)$ DBS during heating cycle.

\footnotetext{
${ }^{4}$ The discrepancy with the transition temperatures estimated from DSC scans is attributed to the sample history such as heating rate, sample container, amount of sample, and the hysteresis of these first order transitions. Also, during XRD measurements, the heating stage used was modified to accommodate aligning magnets which could somewhat change the actual measured temperature.
} 


\section{Conclusion}

The thermotropic behavior of a series of linear catanionic surfactants has been studied. Double-chain catanionic surfactants with dodecyl and tetradecyl ammonium group exist as crystals at room temperature and undergo out-of-equilibrium transition during heating. All the studied surfactants exhibit $\mathrm{Col}_{\mathrm{h}}$ phase before isotropization. This observation is similar to the previously reported findings in catanionic surfactants containing identical headgroups [8,9,24]. $\mathrm{N}\left(\mathrm{C}_{12}\right)$ DBS and $\mathrm{N}\left(\mathrm{C}_{14}\right)$ DBS retain the $\mathrm{Col}_{\mathrm{h}}$ phase for a long period of time (up to 3 days) on cooling to room temperature form the isotropic phase. $\mathrm{N}\left(\mathrm{C}_{18}\right) \mathrm{DBS}$ on the other hand shows a complex phase behavior. In general, quaternary ammonium complexes $\mathrm{N}\left(\mathrm{C}_{n}\right)_{m} \mathrm{DBS}$, with $n=12$ 18 and $m=1,2$ exhibit hexagonal columnar phase. The packing of molecules in the hexagonal phase is influenced by the asymmetry in the hydrocarbon chain length $(n)$ and the number of radial hydrocarbon chains $(m)$.

The thermotropic behavior of these compounds does not follow a regular trend. Over all, isotropization transition temperature decreases with increasing chain length. Also, transition enthalpies are proportional to the molecular ordering. However, the observed transition temperatures, enthalpy, and entropy are influenced by chain length, symmetry, and the number of alkyl groups. These results are in agreement with other literature findings $[11-13,35]$. The thermal stability on the other hand is influenced by the nature of the headgroup [24]. We are currently investigating the thermotropic properties of similar catanionic surfactants synthesized from isomerically pure DBS.

\section{Acknowledgments}

This research was supported by the Organized Research and Creative Activities award to RJ by the University of Houston-Downtown. The US Department of Energy (DOE), Office of Science 
(OS), Basic Energy Sciences (BES) supported the x-ray diffraction measurements performed by

LS, DMA-K, and SK under grant DE-SC-0001412. Use of the National Synchrotron Light

Source (NSLS), Brookhaven National Laboratory (BNL), was also supported by the DOE, OS,

BES under Contract No. DE-AC02-98CH10886. We also thank Dr. Maya Koga for her valuable

assistance with synchrotron x-ray measurements. Undergraduate student participants (TJP and

DJW) were supported by Robert A. Welch Foundation's Departmental Grant to the University of

Houston-Downtown.

Supplementary Materials: Additional DSC, TGA, XRD, and HSPLM data.

\section{References}

[1] C. Tondre, C. Caillet, Properties of the amphiphilic films in mixed cationic/anionic vesicles: a comprehensive view from a literature analysis, Adv. Colloid Interface Sci. 93 (2001) 115-134.

[2] Y. Kondo, H. Uchiyama, N. Yoshino, K. Nishiyama, M. Abe, Spontaneous Vesicle Formation from Aqueous Solutions of Didodecyldimethylammonium Bromide and Sodium Dodecyl sulfate Mixtures, Langmuir 11 (1995), 2380-2384.

[3] P. Jokela, B. Joensson, A. Khan, Phase equilibria of catanionic surfactant-water systems, J. Phys. Chem. 91 (1987) 3291-3298.

[4] C. Tanford, The Hydrophobic Effect: Formation of Micelles and Biological Membranes. second ed., Wiley, New York, 1980, p 233.

[5] E. W. Kaler, K. L. Herrington, A. K. Murthy, J. A. N. Zasadzinski, Phase behavior and structures of mixtures of anionic and cationic surfactants, J. Phys. Chem. 96 (1992) 6698-6707.

[6] A. Khan, E. Marques, in, Catanionic surfactants, Blackie, London, 1997, pp. 37-80.

[7] A. S. Kertes, Solubility and activity of high-molecular amine hydrochlorides in organic solvents, J. Inorg. Nucl. Chem. 27 (1965) 209-217.

[8] A. Caria, A. Khan, Phase Behavior of Catanionic Surfactant Mixtures: Sodium Bis(2ethylhexyl)sulfosuccinate-Didodecyldimethylammonium bromide-Water System, Langmuir 12 (1996) 6282-6290.

[9] R. Jose, T. J. Patel, T. A. Cather, J. Grebowicz, H. Han, P. K. Bhowmik, D. M. AgraKooijman, S. Kumar, Room Temperature Thermotropic Liquid Crystalline Phases of Catanionic Surfactants Derived from Quaternary Ammonium Surfactants and Bis(2ethylhexyl)sulfosuccinate, J. Colloid Interface Sci. 411 (2013) 61-68.

[10] N. Filipovic-Vincekovic, I. Pucic, S.Popovic, V.Tomasic, D.Tezak, Solid-phase transitions of catanionic surfactants, J. Colloid. Interf. Sci. 188 (1997) 396-403.

[11] E. F. Marques, R. O. Brito, Y. Wang, B. F. B. Silva, Thermotropic phase behavior of triple-chained catanionic surfactants with varying headgroup chemistry, J. Colloid. Interf. Sci. 294 (2006) 240-247. 
[12] B. F. B. Silva, E. F. Marques, Thermotropic behavior of asymmetric chain length catanionic surfactants: The influence of the polar head group, J. Colloid. Interf. Sci. 290 (2005) 267-274.

[13] V. Tomasic, S. Popovic, N. Filipovic-Vincekovic, Solid state transitions of asymmetric catanionic surfactants, J. Colloid. Interf. Sci. 215 (1999) 280-289.

[14] M. Blesic, M. Swadzba-Kwasny, J. D. Holbrey, L. J. N. Canongia, K. R. Seddon, L. P. N. Rebelo, New catanionic surfactants based on 1-alkyl-3-methylimidazolium alkylsulfonates, $\left[\mathrm{C}_{\mathrm{n}} \mathrm{H}_{2 \mathrm{n}+1} \operatorname{mim}\right]\left[\mathrm{C}_{\mathrm{m}} \mathrm{H}_{2 \mathrm{~m}+1} \mathrm{SO}_{3}\right]$ : mesomorphism and aggregation, Phys. Chem. Chem. Phys. 11(2009) 4260-4268.

[15] H. L. Nguyen, J. Dedier, H. T. Nguyen, G. Sigaud, Synthesis and characterization of thermotropic amphiphilic liquid crystals: semiperfluoroalkyl- $\beta$-D-glucopyranosides, Liq. Cryst. 27 (2000) 1451-1456.

[16] A. C. Nieuwkerk, A. T. M. Marcelis, A. Koudijs, E. J. R. Sudholter, Ion pair amphiphiles from sodium dodecyl sulfate and ammonium amphiphiles carrying functionalized azobenzene units, Liebigs Ann./Recl. (1997) 1719-1724.

[17] M. S. Gruzdev, N. V. Usol'tseva, L. Torre-Lorente, G. Lattermann, Liquid-crystalline nanocomposites of dendrimers derived from poly(propylenimine) with iron oxide nanoparticle, Izv. Vyssh. Uchebn. Zaved., Khim. Khim. Tekhnol. 49 (2006) 36-40.

[18] W. Dobbs, J.-M. Suisse, L. Douce, R. Welter, Electrodeposition of silver particles and gold nanoparticles from ionic liquid-crystal precursors, Angew. Chem., Int. Ed. 45 (2006) 41794182.

[19] A. Taubert, $\mathrm{CuCl}$ nanoplatelets from an ionic liquid-crystal precursor, Angew. Chem., Int. Ed. 43 (2004) 5380-5382.

[20] Y.-G. Kim, S.-K. Oh, R. M. Crooks, Preparation and Characterization of 1-2 nm Dendrimer-Encapsulated Gold Nanoparticles Having Very Narrow Size Distributions, Chem. Mater. 16 (2004) 167-172.

[21] T. Nishimi, M. Tachikawa, T. Maeda, Y. Ishikawa, T. Kunitake, Alternating molecular arrangements in paired bilayers of oppositely charged amphiphiles, Chem. Lett. 2 (1994) 331334.

[22] P. Somasundaran, H. S. Hanna, Adsorption of sulfonates on reservoir rocks, Soc. Pet. Eng. J. 19 (1979) 221-32.

[23] A. P. Hammersley, S. O. Svensson, A. Hanfland, N. Fitch, D. Hausermann, High Press. Res. 14 (1996) 235.

[24] G. Ungar, V. Tomasic, F. Xie, X.-B. Zeng, Structure of Liquid Crystalline Aerosol-OT and Its Alkylammonium Salts, Langmuir 25 (2009) 11067-11072.

[25] B. Wunderlich, Theory of cold crystallization of high polymers, J. Chem. Phys. 29 (1958) 1395-1404.

[26] Y. Kong, J. N. Hay, The measurement of the crystallinity of polymers by DSC, Polymer 43 (2002) 3873-3878.

[27] P. K. Bhowmik, H. Han, I. K. Nedeltchev, J. J. Cebe, S.-W. Kang, S. Kumar, Synthesis and characterization of ionic liquids: viologen bis \{tetrakis[3,5-bis(trifluoromethyl)phenyl]borate\} salts, Liq. Cryst. 33 (2006) 891-906.

[28] A. J. Jing, O. Taikum, C. Y. Li, F. W. Harris, S. Z. D. Cheng, Phase identifications and monotropic transition behaviors in a thermotropic main-chain liquid crystalline polyether,

Polymer 43 (2002) 3431-3440. 
[29] S. Z. D. Cheng, A. Keller, Standard, The role of metastable states in polymer phase transitions: conecpts, principles and experimental observations, Annu. Rev. Mater. Sci. 28 (1998) 533-562.

[30] A. Keller, S. Z. D. Cheng, The role of metastability in polymer phase transitions, Polymer 39 (1998) 4461-4487.

[31] H. Han, P. K. Bhowmik, Wholly Aromatic Liquid-Crystalline Polyesters, Prog. Polym. Sci. 22 (1997) 1431-1502.

[32] M. A. Yandrasits, S. Z. D. Cheng, A. Zhang, J. Cheng, B. Wunderlich, V. Percec, Mesophase behavior in thermotropic polyethers based on the semi-flexible mesogen 1-(4hydroxyphenyl)-2-(2-methyl-4-hydroxyphenyl)ethane, Macromolecules 25 (1992) 2112-2121.

[33] D. Blunk, K. Praefcke, V. Vill, in: D. Demus, J. W. Goodby, G. W. Gray, H.-W. Spiess, V. Vill (Eds.), in: Handbook of Liquid Crystals High Molecular Liquid Crystals, Vol. 3, WileyVCH, Weinheim, 1998, pp. 305- 340.

[34] L. M. Wingert, G. A. Jeffrey, Jahangir, D. C. Baker, Liquid crystal properties of 4-nalkylphenyl D-glucopyranosides, Liquid Crystal 13 (1993) (3) 467-470.

[35] M. R. A. Matos, B.F. B. Silva, E. F. Marques, Chain length mismatch and packing effects on the thermotropic phase behavior of salt-free catanionic surfactants, Journal of Colloid and Interface Science 405 (2013) 134-144.

[36] A. Ruggirello V. T. Liveri, Study of AOT-stabilized microemulsions of urea dispersed in carbon tetrachloride, Chem. Phys. 288 (2003) 187-195. 